\title{
Efficient Copper Bromide Catalyzed Chemoselective Thioacetalization of Carbonyl Compounds: Selectivity and Scope ${ }^{1}$
}

\author{
Ravi Varala, Sreelatha Nuvula, and Srinivas R. Adapa* \\ Indian Institute of Chemical Technolog, Hyderabad-500007, India. "E-mail: riarala_iictayahoo.coin \\ Received November 18,2005
}

Key Words : Copper bromide (Cu(I)Br), Thioacetalization, Carbonyl compounds, Chemoselectivity

Protections of carbonyl groups as thioacetals are quite often a necessary requirement in the synthesis of multifunctional organic molecules. ${ }^{2}$ Thioacetals are quite stable toward a wide variety of reagents and are useful in organic synthesis as acyl carbanion equivalents in C-C bond-forming reactions. ${ }^{3}$ Further, the use of thioacetals as blocking groups has allowed a new strategy for the electrophilic substitution on the carbonyl compound.

In general, thioacetals are prepared by protic or Lewis acid catalyzed condensation of carbonyl compounds with thiols or dithiols. In the literature there are several methods reported for the preparation of thioacetals from carbony] compounds employing acid catalysts such as $\mathrm{HCl}_{\text {, }}^{\text {ta }}$ $\mathrm{BF}_{3} \cdot \mathrm{OEt}_{2}$, ${ }^{4 \mathrm{~b}} \mathrm{PTSA}^{4 \mathrm{c}} \mathrm{Bu}_{4} \mathrm{NBr}_{3}$, ${ }^{\text {td }} \mathrm{TMSOTf}^{4 \mathrm{e}} \mathrm{SO}_{2},{ }^{+\mathrm{r}} \mathrm{LiBr}^{+\mathrm{c}}$ $\mathrm{LiBF}_{4}{ }^{4 h} \mathrm{AlCl}_{3}, \mathrm{TiCl}_{4}, \mathrm{ZrCl}_{4}$, th $5 \mathrm{M} \mathrm{LiClO}_{4},{ }^{41} \mathrm{InCl}_{3},{ }^{4 \mathrm{~m}}$ $\mathrm{Sc}(\mathrm{OTf})_{3}$, $\mathrm{I}_{2}, \mathrm{Y}(\mathrm{OTf})_{3}, \mathrm{RuCl}_{3}, \mathrm{CoCl}_{2},{ }^{\text {tr }} \mathrm{In}(\mathrm{OTf})_{3}$, th $\mathrm{Bi}\left(\mathrm{NO}_{3}\right)_{3},{ }^{\text {th }} \mathrm{CAN}$, th Ionic Liquid [bmim] $\mathrm{Br}^{\text {th }}$ and $p-\mathrm{TsOH}$ silica gel. ${ }^{4 w}$ However, there are still some drawbacks in these catalytic systems including low yields of the products, ${ }^{\text {td }} \mathrm{long}$ reaction times, ${ }^{\text {th }}$ harsh reaction conditions, ${ }^{4 a c}$ difficulties in work-up, ${ }^{4 . j}$ use of stoichiometric ${ }^{\text {th. }+\mathrm{tr}}$ and/or relatively expensive reagents, ${ }^{+}$and low yields when applied to ketones. Interestingly, only a few of these methods have demonstrated chemoselective protection of aldehydes in the presence of ketones. ${ }^{4 g-t, 4}+\mathrm{m}+\mathrm{th}, 4 \mathrm{c}+\mathrm{q}+\mathrm{tu}, 4 \mathrm{v}$ Thus, the development of efficient and versatile catalytic system for thioacetalization is an active ongoing research area and there is still some scope for further improvement.

In continuation of our interest in developing nove] synthetic methodologies, particularly carbon-carbon, carbonheteratom bond formations, herein, we report a new protocol that employs air stable copper salts as efficient catalyst in the thioacetalization of a variety of carbonyl compounds under mild conditions as they are readily available and much cheaper than the reagents that are listed above. Advantages of the protocol include high-yielding reactions that can be conducted at ambient temperature. Recently, there has been growing considerable interest in the use of copper halides, particularly copper bromide $(\mathrm{CuBr})$ in organic synthesis. ${ }^{6}$

In this paper, we report that $\mathrm{CuBr}$ catalyzes transformation of aromatic and aliphatic aldehydes and ketones, to their corresponding thioacetals in excellent yields at room temperature (Scheme 1). To the best of our knowledge, there are no earlier reports on thioacetalization using $\mathrm{CuBr}$ as catalyst.

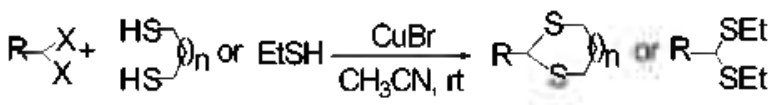

$$
\begin{aligned}
& \mathrm{R}=\mathrm{aryl}, \text { alkyl, heterocyclic } \\
& x X=0 \\
& \mathbf{n}=0,1
\end{aligned}
$$

Scheme 1

Table 1. Comparision of different reagents as catalysts in thioacctalization between benzaldehyde and ethanethiol

\begin{tabular}{ccc}
\hline Entry & Catalyst & Isolated yield $(\%)^{\circ}$ \\
\hline 1 & $\mathrm{CuCl}$ & 70 \\
2 & $\mathrm{CuBr}$ & 85 \\
3 & $\mathrm{CuI}$ & 62 \\
4 & $\mathrm{Pd}(\mathrm{acac})_{2}$ & 52 \\
5 & $\mathrm{Co}(\mathrm{acac})_{3}$ & 45 \\
6 & VO(acac) & 0 \\
7 & Ru(acac) & 0 \\
\hline
\end{tabular}

Standard conditions: $1 \mathrm{mmol}$ benzaldehyde, $1.2 \mathrm{mmol}$ ethanethiol, 5 mol\% catalyst, $\mathrm{CH}_{3} \mathrm{CN}$, th, 8 h. "Yields tefer to pure isolated products.

The screening of several reagents chosen, allowed us to shortlist $\mathrm{CuBr}$ as the suitable catalyst to affect this transformation. At first, we tested the efficacy of different reagents in terms of yields towards the standardized thioacetalization of benzaldehyde with ethanethiol in acetonitrile at ambient temperature during 8 hours.

Among the reagents, $\mathrm{CuBr}$ (entry 2, Table 1), $\mathrm{CuCl}$ (entry 1 , Table 1) gave fair yields in $30 \mathrm{~min}$. Cul gave moderate yield (entry 3, Table 1) after $2 \mathrm{~h}$. Other reagents $\mathrm{Co}(\mathrm{acac})_{3}$, $\mathrm{Ru}(\mathrm{acac})_{3}, \mathrm{Pd}(\mathrm{acac})_{2}$, VO(acac) (See Table 1) gave less or no yields even after $8 \mathrm{~h}$. As seen in Table 1 , the protected thioacetal for benzaldehyde was obtained in $85 \%$ yield in 30 min, at ambient temperature using $\mathrm{CuBr}$ as catalyst and acetonitrile as solvent. Competitive experiments were carried out with and without $\mathrm{CuBr}$ in acetonitrile. The reactions could be performed in different organic solvents such as $\mathrm{CHCl}_{3}, \mathrm{CH}_{2} \mathrm{Cl}_{2}$, acetonitrile, toluene, and dioxane efficiently. Acetonitrile was the best among the tested solvents in tems of yields and time. It should be pointed out that in the absence of $\mathrm{CuBr}$ the reactions did not proceed in acetonitrile even after prolonged reaction times thus confirming the effectiveness of the $\mathrm{CuBr}$ as catalyst for thiacetalization. A catalytic amount of $\mathrm{CuBr}(5 \mathrm{~mol} \%)$ is sufficient to obtain the 
desired compounds in good yields. No significant improvement in the yields was observed on increasing the catalyst loading further.

With optimized experimental conditions for benzaldehyde with ethanethiol in hand (Scheme 1), the generality of this process has been proved with a wide range of aromatic, aliphatic and heterocyclic aldehydes, and ketones as well, in the presence of catalytic amounts of $\mathrm{CuBr}$; the results are illustrated in Table 2. As shown in Table 2, various types of aromatic aldehydes with electron-donating and electronwithdrawing groups were cleanly and rapidly converted to the corresponding dithianes and dithiolanes in the presence of $5 \mathrm{~mol} \%$ of $\mathrm{CuBr}$ (entries 1-3, 5-11, Table 2 ).

Aliphatic and $\alpha \beta$-unsaturated aldehydes were also thioacetalized in good yields (entries 4, 15 and 16). Similarly $\alpha, \beta$-unsaturated ketones such as cyclohexenone (entry 18) reacted with 1,2-ethanedithiol to give the corresponding product in good yields. The protection of heteroaromatic ( 12 and 13) aldehydes was also carried out under similar reaction conditions and the results are summarized in the Table 2. For example, furfural (entry 12) gave the thioacetalized product moderately, whereas entry 13, 2-pyridine carboxaldehyde, resulted the corresponding thioacetal in low yield even after prolonged time. It is noteworthy that $\mathrm{N}, \mathrm{N}-$ dimethyl aniline, entry 6 , gave moderate yield of $55 \%$ even after using $5 \mathrm{~mol} \%$ of catalyst to furmish the corresponding product. ${ }^{49} \mathrm{~N}$-phthalimido acetaldehyde on reacting with 1,2ethanedithiol to give the corresponding product in moderate yield (entry 14). In general, aldehydes react much faster than ketones with thiols to yield corresponding thioacetals. Among ketones studied herein, aliphatic ketones reacted much faster than aromatic ketones with thiols to yield corresponding thioacetals (entries 17-20).

The feasibility of recovery and reuse of the catalyst in the present methodology was also examined through a series of sequential thioacetalization of $p$-methoxy benzaldehyde as model substrate (entry 7 , Table 2 ). In a typical reaction, the aqueous layer containing the catalyst could be evaporated under reduced pressure to give a solid which is identical to that of the commercially available salt as confinmed by FTIR spectrum (see experimental section) and reused for 3 cycles.

Table 3. Results of recycling and reuse of $\mathrm{CuBr}$ in thioacetalization of $p$-methoxy benzaldehyde as model substrate (entry 7 , Table 2 ).

The fact that, for the second and third recyclings, the yields are lowered for good conversion of the desired product clearly indicates that some loss of the catalyst must have occurred during the reaction and workup with slight loss of activity too (Table 3 ).

It is clearly evident from Table 2, that in general the reaction with aldehydes takes place rapidly in the presence of $\mathrm{CuBr}$ in comparison to those with ketones. These results prompted us to explore the chemoselective protection of aldehydes in the presence of ketones. It is noteworthy that ketones did not produce the corresponding thioacetals under the same reaction conditions. For example, when an equimolar mixture of benzaldehyde and acetophenone was
Table 2. CuBr-catalyzed protection of carbonyl compounds as dithiolanes, dithianes or diethyl dithioacetals at room temperature

\begin{tabular}{|c|c|c|c|c|}
\hline Entry & Substrate & Reagent & Time & Yield $(\%)^{a}$ \\
\hline \multirow{3}{*}{1} & & A & $30 \mathrm{~min}$ & 85 \\
\hline & & B & $15 \mathrm{~min}$ & 92 \\
\hline & & C & $30 \mathrm{~min}$ & 88 \\
\hline 2 & & B & $45 \mathrm{~min}$ & 90 \\
\hline 3 & & B & $45 \mathrm{~min}$ & 85 \\
\hline 4 & & B & $60 \mathrm{~min}$ & 89 \\
\hline 5 & & B & $5 \mathrm{~h}$ & 60 \\
\hline 6 & & B & $24 \mathrm{~h}$ & 55 \\
\hline 7 & & B & $60 \mathrm{~min}$ & $92 / 74^{b}$ \\
\hline 8 & & B & $2 \mathrm{~h}$ & 80 \\
\hline 9 & & B & $45 \mathrm{~min}$ & 85 \\
\hline 10 & & $\begin{array}{l}\mathrm{B} \\
\mathrm{C}\end{array}$ & $\begin{array}{l}5 \mathrm{~h} \\
6 \mathrm{~h}\end{array}$ & 17 \\
\hline 11 & & B & $30 \mathrm{~min}$ & 85 \\
\hline 12 & & B & $12 \mathrm{~h}$ & 58 \\
\hline 13 & & B & $24 \mathrm{~h}$ & 20 \\
\hline 14 & & B & $12 \mathrm{~h}$ & 58 \\
\hline 15 & & $\begin{array}{l}\text { A } \\
B\end{array}$ & $\begin{array}{l}30 \mathrm{~min} \\
30 \mathrm{~min}\end{array}$ & $\begin{array}{l}85 \\
80\end{array}$ \\
\hline 16 & & B & $45 \mathrm{~min}$ & 72 \\
\hline 17 & & B & $6 \mathrm{~h}$ & 60 \\
\hline 18 & & B & $8 \mathrm{~h}$ & 78 \\
\hline 19 & & B & $24 \mathrm{~h}$ & 55 \\
\hline 20 & & B & $18 \mathrm{~h}$ & 60 \\
\hline
\end{tabular}

Reagent: $\left.\mathrm{A}: \mathrm{EtSH} ; \mathrm{B}: \mathrm{SH}\left(\mathrm{CH}_{2}\right)_{2} \mathrm{SH} ; \mathrm{C}: \mathrm{SH}_{2} \mathrm{CH}_{2}\right)_{3} \mathrm{SH}$

'Tsolated yields after column chromatography. 'Tsolated yields with reused catalyst (yield after third cycle). 
Table 3. Results of recycling and reuse of $\mathrm{CuBr}$ in thioacetalization of $p$-incthoxy benzaldehyde as model substrate (entry 7, Table 2)

\begin{tabular}{ccccc}
\hline Cycle & 1 & 2 & 3 & 4 \\
\hline Yield $(\%)^{\prime \prime}$ & 92 & 88 & 80 & 74 \\
\hline
\end{tabular}

Tsolated yields with reused catalyst (recovered catalyst 90, 82, 75\% tespectively).
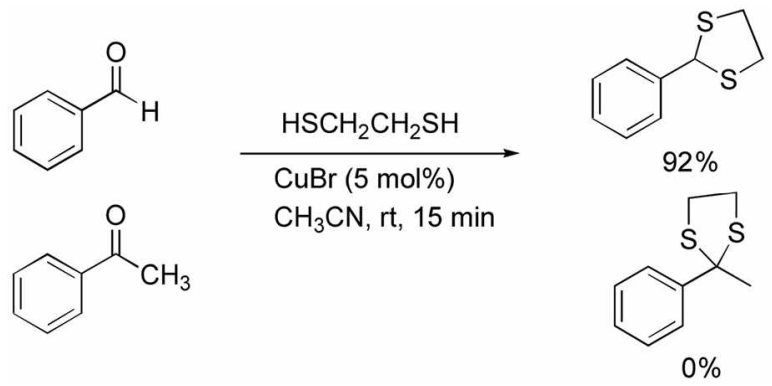

Scheme 2

allowed to react with 1,2-ethanedithiol (2.5 equivs.) in the presence of catalytic amount of $\mathrm{CuBr}$ only the 1,3-ditholane derivative of the benzaldehyde was obtained (Scheme 2). Furthermore, it was also observed that the aliphatic ketone, cyclohexanone, could be selectively protected in the presence of the aromatic ketone, acetophenone, by employing the present methodology (Scheme 3). This is because aliphatic ketones react much faster than aromatic ketones under our experimental conditions. The differences of reactivities of the aldehydes and ketones suggest that this method can be used for the selective protection of these groups, and resulted in the successful protection of an aldehyde in the presence of a ketone.

In comparision with the most of the catalysts reported in the thioacetalization of benzaldehyde, ${ }^{4} \mathrm{CuBr}$ employed here shows significant catalytic activity than others in terms of the catalyst loading, cost, yie]ds and reaction times.

In summary, the present $\mathrm{CuBr}$-catalyzed method of protection of carbonyl compounds as thioacetals is a novel, generally applicable, mild, cost-effective, operational simplicity and convenient one, where the catalyst could be readily recovered and reused thus making this procedure environmentally benign. Furthemore, the relatively slow reaction rate of ketones allows for chemoselective protection of aldehydes in the presence of ketones, making this is an important tool in synthetic organic chemistry. Efforts to expand the scope of the reaction in green solvents and deprotection of thioacetals are currently underway in our laboratory.

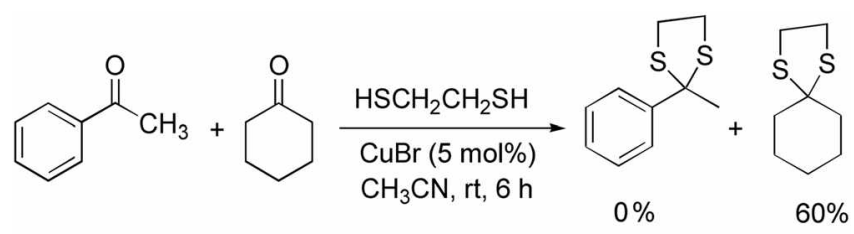

Scheme 3

\section{Experimental Section}

To a stirred solution of carbonyl compound ( $1 \mathrm{mmol})$ and thiol $(1.2 \mathrm{mmol})$ in acetonitrile $(2 \mathrm{~mL})$ was added $5 \mathrm{~mol} \%$ $\mathrm{CuBr}$. After a period specified in Table 2, water $(5 \mathrm{~mL})$ was added to the reaction mixture, which was then extracted with dichloromethane. The crude product was purified by short silica gel column chromatography to fumish the corresponding thioacetal. The aqueous layer containing the catalyst could be evaporated under reduced pressure to give a solid which is identical to that of the commercially available salt as confirmed by IR spectrum and reused for the next thioacetalization reactions, without losing any significant activity (Table 2, entry 7). Most of the products are known and were determined using comparison of their physical and spectral data with those reported in the literature and all new compounds gave satisfactory spectral data in accordance to their proposed structures.

Acknowledgments. V. R is thankful to the DIICT, J.S. Yadav and Council of Scientific Industrial Research (CSIR, India) for the award of Senior Research Fellow.

\section{References}

I. IICT Communication no: 050614 .

2. (a) Greene, T. W.; Wuts, P. G. M. Protective Grotps in Organic Synthesis, $3^{\text {rd }}$ ed.; Wiley: New York, $1999 ;$ p 329 . (b) Yus, M.; Najera, C.; Foubelo, F. Tetrohedron 2003, 59,6147.

3. (a) Corey, E. J.; Seebach, D. J. Org. Chem. 1966, 31, 4097. (b) Seebach, D. Synthesis 1969, 17. (c) Grobel, B.-T,; Seebach, D. Synthesis 1977, 357. (d) Seebach, D. Angew. Chem. Int. Ed. Engl. 1979, 18, 239. (e) Page, P. C. B.; van Niel, M. B.; Prodget, J. Tetrahedron 1989, 45, 7643. (f) Kocienski, P. J. Protecting Groups, 3rd ed.; Thieme: Stuttgart, 2004.

4. There have been a number of reports on the protection of carbony! compounds as dithioacetals. (a) HCl: Ralls, J. W; Dobson, R. M.; Reigel, B. J. Am. Chem. Soc, 1949, 7l, 3320. (b) BFy $\mathrm{H}_{2} \mathrm{O}$ : Fieser, L. F. J. Am. Chen. Soc. 1954, 76, 1945. (c) PTSA: Djerassi, C.; Gorman, M. J. Ani. Cheni. Soc. 1953, 75, 3704. (d) $\mathrm{Bu}_{4} \mathrm{NBr}_{3}$ : Mondal, E.; Sahu, P. R.; Bose, G.; Khan, A. T. Tetrahedron Lett. 2002, 43, 2843. (e) TMSOTf: Ravindranathan, T.; Chavan, S. P.; Dantaled, S. W. Tetrahedron Lett. 1995, 36, 2285. (f) $\mathrm{SO}_{2}$ : Burczyk, B.; Kortylewicz, Z. Synthesis 1982, 831. (g) LiBr: Firouzabadi, H.; Iranpoor, N.; Karimi, B. Synthesis 1999, 58. (h) $\mathrm{LiBF}_{4}$ : Yadav, J. S.; Reddy, B. V. S.; Pandey, S. K. Syment 2001 , 238. (i) $\mathrm{AlCl}_{3}$ : Ong, B. S. Tetrahedron Lett, 1980, 2I, 4225. (j) TiCL: Kumar, V.; Dev, S. Tetrahedron Lett. 1983, 24, 1289. (k) ZrCl. Karimi, B.; Seradj, H. Symlett 2000, 805, (l) 5M LiClO4: Saraswathy, V. G.; Sankararaman, S. J. Org. Chem. 1994, 59, 4665. (m) $\mathrm{InCl}_{3}$ : Muthusany, S.; Babu, S. A.; Gunanathan, C. Tetrahedron Lett. 2001, 42, 359. (n) Sc(OTf)s: Kamal, A.; Chouhan, G. Tetrahedron Lett. 2002, 43, 1347. (o) $\mathrm{I}_{2}$ : Firouzabadi, H.; Iranpoor, N.; Hazarkhani, H. J. Org. Chem. 2001, 66, 7527. (p) Y(OTf) 3: De, \$. K. Tetrahedron Lett. 2004, 45, 2339. (q) De, S. K. Adw. Sywh. Catal. 2005, 347, 673, (r) $\mathrm{CoCl}_{2}$ : De, S. K.

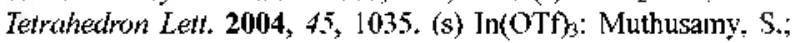
Babu, S. A.; Gunanathan, C. Tetrahedron 2002, 58, 7897. (t) $\mathrm{Bi}\left(\mathrm{NO}_{3}\right)_{2}:$ Stivastava, N.; Dasgupta, S. K.; Banik, B. K. Tetrahedron Lett. 2003, 44, 1191. (u) CAN: Mandal, P. K.; Roy, S. C. Tetrahedron 1995, 51, 7823. (v) Jonic liquid [bmim]Br: Kamal, A.; Chouhan, G Ad: Syth. Catal, 2004, 346, 579. (w) p-TsOH/ silica gel: Ali, M. H.; Gomes, M. G. Sythesis 2005, 1326. 
5. (a) Varala, R.; Ramu, E.; Alam, M. M.; Adapa, S. R. Syłtetf 2004. 1747. (b) Varala, R.; Ramu, E.; Alam, M. M.; Adapa, S. R. Chent. Lett. 2004, 33, 1614. (c) Varala, R.; Ramu, E.; Adapa, S. R. Bull. Chem. Soc. Jpn. 2006, 79, 140. (d) Varala, R, Alam, M. M.; Adapa, S. R. Synlett 2003, 720. (e) Alam, M. M.; Varala, R.; Adapa, S. R. Tetrahedron Lett, 2003, 5115 . (f) Varala, R.; Alam, M. M.; Adapa S. R. Synletf 2003, 67. (g) Varala, R.; Ramu, E.; Sreelatha, N.; Adapa, S. R. Tetrahedron Lett. 2006, 47, 877. (h) Alam, M. M.; Varala, R.; Ramu, E.; Adapa, S. R. Left. Org. Chem.
$2006,3,187$.

6. (a) Xu, L.-W.; Li, J.-W.; Xia, C.-G.; Zhou, S.-L.; Hu, X.-X. Sythlett 2003, 2425. (b) Park, S. B.; Alper, H. Chem. Contmith. 2005, 1315. (c) Li, Z.; Li, C.-J. J. Am. Chem. Soc. 2004, 126, I1810. (d) Li, C.-J. Wei, C. Chem. Commun. 2002, 268. (e) Gommermann, N.; Koradin, C.; Polborn, K.; Knochel, P. Angew, Chem. Int. Ed. 2003, 42, 5763. (f) Koradin. C.; Gommermann, N.; Polborn. K. Knochel, P. Chem. Etr. J. 2003, 0, 2797. (g) Li, Z;; Li, C.-J. Etr. J. Org. Chent. 2005, 15, 3173. 